\title{
LA PROTECCIÓN DEL NASCITURUS EN EL PROCESO DE DIVORCIO
}

Manuel Garabal

Email: manuelf@garabal.com

RESUMEN: En el proceso de divorcio habiendo hijos no natos es menester el establecimiento de medidas provisionales que fijen una cuantía para satisfacer las necesidades del nasciturus - tales como ecografías, clases de preparación del parto, etc. - así como que tales medidas varíen a lo largo del crecimiento del hijo para adecuarse a las necesidades de cada momento en vez del establecimiento de una cuantía que no varíe con las necesidades, necesitándose en dicho proceso la presencia de un mediador imparcial que permita la viabilidad de la presente teoría.

PALABRAS CLAVE: Nasciturus, divorcio, viabilidad, mediación

\begin{abstract}
In the divorce proceedings having unborn children is necessary the imposition of provisional measures to set an amount to meet the needs of the unborn child - such as sonograms, childbirth preparation classes, etc. - And that such measures vary throughout the growing child to suit the needs of the moment rather than the establishment of an amount that does not vary with the needs, requiring in this process the presence of an impartial mediator that allows the viability of this theory.
\end{abstract}

KEYWORDS: Unborn child, divorce, mediation, feasibility 


\section{$\underline{\text { INTRODUCCIÓN }}$}

El matrimonio, como institución, consiste en una unión dotada de estabilidad entre dos personas físicas que, con arreglo a diversas formalidades, tiene el fin de compartir vida y existencia ${ }^{1}$.

Fruto del mismo concepto ambas partes pueden considerar pertinente la tenencia de descendientes $^{2}$

Con la consideración del matrimonio como un "proceso" - más que como una institución - puede haber un fin en el que no sólo son partes afectadas los cónyuges, sino que lo son también los hijos. ${ }^{3}$

\section{FIGURA DE LOS CÓNYUGES CON RESPECTO AL NASCITURUS}

Con el fin del matrimonio podría determininarse la existencia de un segundo proceso considerado por el derecho procesal - en el cual es necesario preservar los intereses de los hijos ${ }^{4}$, en especial es menester preservar los intereses de los hijos no natos o nasciturus 5 .

\footnotetext{
${ }^{1}$ SÁNCHEZ CALERO: "Curso de derecho civil IV. Derecho de Familia y sucesiones", pág. 57, Tirant lo Blanch, Valencia 2005.

${ }^{2}$ BERCOVITZ RODRIGUEZ-CANO, Rodrigo: "Manual de Derecho Civil. Derecho de familia", Bercal, s.a., págs. 17-22, Madrid, 2003.

${ }^{3}$ BERCOVITZ RODRIGUEZ-CANO, Rodrigo: "Manual de Derecho Civil. Derecho de familia", Bercal, S.A., págs. 100, 209-211, Madrid, 2003.

${ }^{4}$ BERCOVITZ RODRIGUEZ-CANO, Rodrigo: "Manual de Derecho Civil. Derecho de familia", Bercal, S.A., págs. 209- 211, Madrid, 2003.

${ }_{5}^{5}$ SÁNCHEZ CALERO: "Curso de derecho civil IV. Derecho de Familia y sucesiones", pág. 34,109 y 209; Tirant lo Blanch, Valencia 2005. ( TODO ELLO SOBRE EFECTOS DE FILIACIÓN);

REQUEJO CONDE, Carmen, ALISTE SANTOS, Tomás J.: «La protección histórica al concebido y su proyección en el Derecho Civil español actual», en Actualidad Civil (LA LEY). Revista núm. 4. Fecha de
} 
Para preservar los derechos del mismo se partirá que los hijos sean consecuencia de la generación biológica o la procreación en tanto en cuanto los cónyuges hayan estado casados entre sí ( véase lo definido en el artículo 108.1 CC al establecer que "La filiación puede tener lugar por naturaleza y por adopción. La filiación por naturaleza puede ser matrimonial y no matrimonial. Es matrimonial cuando el padre y la madre están casados entre sí"). Eso sí, se permitirá probar la paternidad - conforme al artículo 39.2 CE - aunque la misma admitirá la prueba en contrario. Para ello es necesario analizar dos principios, tal y como determina Espinosa Infante: Libre investigación de paternidad, teniendo en cuenta las cautelas necesarias; no absolutividad biológica. ${ }^{6}$

La "madre" se presume válida por razones biológicas (mater ser certa est), lo cual se demostrará una vez producido el parto, es decir, produce efectos una vez que tiene lugar (art. $122 \mathrm{CC}$ ), con lo que se afirma que prevalece el nacimiento. ${ }^{7}$

En cuanto al "padre" se presume el marido de la madre y, si hay separación por sentencia se requiere demostrar convivencia para que la presunción "pater vero est" despliegue su eficacia. Además, de acuerdo con el artículo $116 \mathrm{CC}$, "se presumen hijos del marido los nacidos después del matrimonio y antes de los 300 días siguientes a su disolución o a la separación de hecho o legal de los cónyuges". ${ }^{8}$

publicación: Quincena del 16 al 29 de febrero de 2008. Sección: A Fondo, págs. 383 a 402, Tomo: 1 (LA LEY187/2008).

${ }^{6}$ ESPINOSA INFANTE, José Miguel: "Derecho civil. Derecho de familia: Contestaciones al programa de oposiciones a notarias";, pág. 417, Dykinson, 2006, Madrid

${ }^{7}$ ESPINOSA INFANTE, José Miguel: "Derecho civil. Derecho de familia: Contestaciones al programa de oposiciones a notarias”; pág. 409 y 415, Dykinson, 2006, Madrid

${ }^{8}$ ESPINOSA INFANTE, José Miguel: "Derecho civil. Derecho de familia: Contestaciones al programa de oposiciones a notarias";, pág. 411, Dykinson, 2006, Madrid

ALISTE SANTOS, Tomás J.: «La protección histórica al concebido y su proyección en el Derecho Civil español actual», en Actualidad Civil (LA LEY). Revista núm. 4. Fecha de publicación: Quincena del 16 al 29 de febrero de 2008. Sección: A Fondo, págs. 383 a 402, 
En lo relativo a la protección de la filiación y sus efectos, es menester hacer referencia la Sentencia de 8 julio 1986. RJ 1986\4423, según la cual ésta quedará probada "«aunque no haya prueba directa de la generación», la filiación podrá declararse si resulta del «reconocimiento expreso o tácito, o de la posesión de estado, de la convivencia con la madre en la época de la concepción, o de otros hechos de que se infiera la filiación de modo análogo»" $"$.

Como consecuencia de la filiación surgen efectos tales como la necesidad de relaciones personales, patria potestad o alimentos - para ambos cónyuges -. Dichos efectos se hallarán en suspensión hasta que se produzca el nacimiento del descendiente. En el analizado proceso de divorcio deberán de establecerse medidas provisionales en lo relativo a los efectos de la filiación los cuales estarán supeditados a los artículos 29 ("E1 nacimiento determina la personalidad; pero el concebido se tiene por nacido para todos los efectos que le sean favorables, siempre que nazca con las condiciones que expresa el artículo siguiente". Véanse: - Artículos 14 a 38 de la Constitución Española. - Artículos 627 y 959 a 967 de este Código. - Artículos 53 y 54 de la Ley de Registro Civil. - Ley $35 / 2007$, de 15 de noviembre, por la que se establece la deducción por nacimiento o adopción en el Impuesto sobre la Renta de las Personas Físicas y la prestación económica de pago único de la Seguridad Social por nacimiento o adopción) y 30 CC ("La personalidad se adquiere en el momento del nacimiento con vida, una vez producido el entero desprendimiento del seno materno") - redactado por la disposición final tercera de la Ley 20/2011, de 21 de julio, del Registro Civil («B.O.E.» 22 julio).Vigencia: 23 julio 2011 ya que surtirán efecto una vez se produzca el nacimiento ergo el individuo adquiere personalidad y con ello los derechos personalísimos del mismo - así como el entero desprendimiento del seno materno ${ }^{10}$.

En palabras de la doctora De la Iglesia Monje "El nacimiento determina la personalidad pero al concebido se tiene por nacido para todos los efectos que le sean favorables siempre que tuviere figura humana y viviere veinticuatro horas enteramente desprendido del seno materno",11.

\footnotetext{
${ }^{9}$ Jurisdicción: Civil; Ponente: Excmo. Sr. Jaime Santos Briz

${ }^{10}$ Ley 20/2011, de 21 de julio, del Registro Civil («B.O.E.» 22 julio).Vigencia: 23 julio 2011;
}

ESPINOSA INFANTE, José Miguel: "Derecho civil. Derecho de familia: Contestaciones al programa de oposiciones a notarias"; pág. 412, Dykinson, 2006, Madrid

${ }^{11}$ De La Iglesia Monje, María Isabel: “La Protección Del Nasciturus Y Su Proyección En La 
Los derechos relacionados con alimentos serán del descendiente hijo del ex marido de la madre, con carácter inmediato al nacimiento y de naturaleza personalísima, aunque los deberá de administrar el cónyuge que tenga la guarda y custodia del recién nacido, que en este caso será la madre ${ }^{12}$.

\section{JURISPRUDENCIA EN MATERIA DE LA PROTECCIÓN DEL NASCITURUS EN $\underline{\text { EL PROCESO DE DIVORCIO }}$}

La jurisprudencia ha asentado varios precedentes en lo relativo a la protección del nasciturus en el proceso de divorcio.

En primer lugar, la Sentencia del Juzgado de Primera Instancia número 3 de San Sebastián en mayo de 2004 según la cual se aprueba el convenio regulador - con el correspondiente consentimiento de la Fiscalía de Guipúzcoa - acordándose pensión para el alimento del recién nacido y régimen de visitas, los cuales se hallarán en suspenso hasta el nacimiento - que la madre deberá de probar con su posterioridad para poder recibir los mismos y administrarlos -.

En segundo lugar, la Sentencia de la Audiencia Provincial de Pontevedra sala 3 del 29 de febrero del 2000 - SAP $63 / 2000^{13}$ - , donde se define que la concesión de alimentos sea en favor del feto, además de considerarlo como un derecho propio del nasciturus a consecuencia del artículo $29 \mathrm{CC}^{14}$, pero no como " un derecho futuro" ("MEDIDAS DERIVADAS DE SEPARACIÓN, DIVORCIO Y NULIDAD MATRIMONIAL. RESPECTO DE LOS HIJOS. DERECHO DE VISITAS. La ley reconoce al padre el derecho a visitar a su hijo pero que en breve será mayor de edad y se deberá estar a su

\footnotetext{
Jurisprudencia Civil Actual".

${ }^{12}$ Sentencia núm. 282/2012 de 26 abril. JUR 2012\180445 (SOBRE LOS EFECTOS DE LA FILIACIÓN Y LA MODIFICACIÓN DE LA PENSIÓN ALIMENTICIA). Jurisdicción: Civil; Recurso de Apelación núm. 200/2012; Ponente: IIlmo. Sr. D Carlos Moreno Millán

13 Ponente: Antonio J. Gutiérrez R. Moldes; Fecha de Resolución: 29 de Febrero de 2000; Número de Resolución: 63/2000; Emisor: Audiencia Provincial - Pontevedra.
}

${ }^{14}$ Ley 20/2011, de 21 de julio, del Registro Civil («B.O.E.» 22 julio).Vigencia: 23 julio 2011 
voluntad, así en la exploración se mostró contrario a las visitas de su padre ya que antes su padre dejó de comunicarse con él aunque si se le reconoce tal derecho pero...")

En tercer lugar, la Sentencia de la Audiencia Provincial de Toledo del 20 de febrero de $2003^{15}$, la cual reconoce la prestación de alimentos con anterioridad al nacimiento.

En cuarto lugar es menester comparar dos sentencias que establecen dos puntos de vista opuestos. La Sentencia de la Audiencia Provincial de Alicante de 4 de octubre de 2005 ${ }^{16}$ y la Sentencia de la Audiencia Provincial de Toledo de 31 de julio de $2003^{17}$.

La Sentencia de la Audiencia de Alicante reconoce que la prestación ha de ser acorde con la cantidad mínima necesaria para vivir, mientras que la Sentencia de la Audiencia de Toledo define que ha de ser acorde con las necesidades del recién nacido, además de que debe variar con el paso del tiempo en función de las necesidades reales, no pudiendo fijarse las medidas provisionales fundadas en dicho hecho.

En quinto lugar dar especial importancia a la Sentencia de la Audiencia Provincial de Barcelona del 30 de marzo de $2006^{18}$. La sentencia plantea la solicitud de la ex pareja del uso y disfrute de la vivienda propiedad del ex marido - pero de uso como vivienda familiar durante el matrimonio - alegando que debe de hacer uso de ella en atención de las necesidades del nasciturus. Finalmente el Tribunal rechaza la propuesta ya que no se puede privar a un propietario del uso y disfrute de su vivienda atendiendo a dicha finalidad.

\footnotetext{
15 De La Iglesia Monje, María Isabel: "La Protección Del Nasciturus Y Su Proyección En La Jurisprudencia Civil Actual".

16 Sentencia núm. 414/2005 de 4 octubre. JUR 2008\141067 Historia del Caso; Jurisdicción: Civil; Recurso de Apelación núm. 529/2005; ponente: IIlmo. Sr. D María de las Mercedes Matarredona Rico.

${ }^{17}$ Sentencia núm. 413/2003 de 31 julio. JUR 2008\159189 Historia del Caso; Jurisdicción: Civil, Recurso de Apelación núm. 230/2003, ponente: IIlmo. Sr. D Fernando Cambronero Cánovas

${ }^{18}$ Sentencia núm. 218/2006 de 30 marzo. JUR 2006\246601; Jurisdicción: Civil; Recurso de Apelación núm. 508/2005; Ponente: IIlmo. Sr. D Fernando Utrillas Carbonell
} 
En sexto y último lugar la Sentencia de la Audiencia Provincial de A Coruña 97/2001 del 23 de marzo, según la cual el nacimiento del nasciturus tras la aprobación de las medidas provisionales es motivo fundamental para la modificación de las mismas. Dicha sentencia establece que "se tuvo en cuenta que la esposa estaba embarazada de unos 8 meses, pero paradójicamente no se hizo ninguna referencia a la futura hija ni se previó nada al respecto. Por ello hay que entender que el nacimiento de esa hija y la obligación del padre de atender a sus alimentos, supone ya por sí misma una modificación de las circunstancias tenidas en cuenta al llegar a ese pacto".

Con ello se refuerza la teoría doctrinal acerca de la modificación de la pensión alimenticia en función de las necesidades del nasciturus ${ }^{19}$.

Tal y como dice la sentencia se trata de "pensión por desequilibrio: reducción de la cuantía: procedencia: establecida en atención al embarazo de la madre, sin tener en cuenta el derecho a los alimentos del «nasciturus»: distribución del importe en los dos conceptos".

\section{CONCLUSIONES}

La protección del nasciturus se haya en auge en la actualidad con sentencias como las anteriormente planteadas aunque deberían de tiene que analizarse la problemática sobre los gastos anteriores al nacimiento así como la creación de una doctrina unitaria que defina la existencia de medidas reguladoras en alimentos que sean debidamente contabilizadas y varíen en función de las necesidades vitales y biológicas de los descendientes junto con que los efectos sean debidamente favorables al nasciturus ya que en palabras de la doctora De la Iglesia Monje “ La protección sustantiva genérica del nasciturus que en nuestro ordenamiento jurídico se encuentra históricamente ligada al Derecho Civil ha evolucionado hacia otras esferas de protección, el Derecho Público. La jurisprudencia le otorga la indemnización por daño moral, reconoce su capacidad para ser beneficiario de una suma asegurada en el seguro de vida para caso de

19

Sentencia núm. 97/2001 de 23 marzo. JUR 2001\178683 Jurisdicción: Civil; Recurso de Apelación núm. 483/2000

Ponente: IIlmo. Sr. D José Ramón Sánchez Herrero 


\section{Doctrina y Jurisprudencia}

fallecimiento, pensión alimenticia, condición de donatario, heredero, legatario, parte en un proceso... pero también le declara en desamparo como consecuencia de la situación de alto riesgo social de la familia". ${ }^{20}$

Por tanto, a partir de esta investigación puede determinarse la existencia de dos teorías doctrinales. Por una parte aquella la cual establezca que la pensión alimenticia sea invariable y, por otra parte aquella la cual establezca que la pensión alimenticia debe de variar en función de las necesidades - primero del nasciturus y posteriormente del hijo nato -. Además sería necesario el estudio por parte de los órganos judiciales de la existencia de pensión para los gastos del nasciturus en las medidas provisionales del divorcio previo el nacimiento. La presencia de un mediador imparcial - véase mismo el Ministerio Fiscal - garantizaría la viabilidad de dicha teoría.

\footnotetext{
${ }^{20}$ AP de Badajoz, Sección 1. , , sentencia de 11 de noviembre de 2002, recurso 187/2002. Ponente: Jesús Plata García. Número de sentencia: 67/2002. Número de recurso: 187/2002.
} 